\title{
Structural Characterization and Thermal Behavior of a Novel Energetic Material: 1-Amino-1-(2,4-dinitrophenylhydrazinyl)-2,2-dinitroethylene
}

\author{
Xiaolei Ren, Xiangang Zuo ${ }^{\dagger}$ Kangzhen Xu, ${ }^{*}$ Yinghui Ren, Jie Huang, Jirong Song, Bozhou Wang, and Fengqi Zhao ${ }^{\ddagger}$ \\ Department of Chemical Engineering, Northwest University, Xi'an 710069 China. *E-mail: xukz@nwu.edu.cn \\ ${ }^{\dagger}$ College of Information Engineering, Henan Institue of Science and Technology, Xin'xiang 453003, China \\ ${ }^{\ddagger} X i$ 'an Modern Chemistry Research Institute, Xi'an 710065, China \\ Received March 2, 2011, Accepted May 22, 2011
}

\begin{abstract}
A novel energetic material, 1-amino-1-(2,4-dinitrophenylhydrazinyl)-2,2-dinitroethylene (APHDNE), was synthesized by the reaction of 1,1-diamino-2,2-dinitroethylene (FOX-7) and 2,4-dinitrophenylhydrazine in $N$ methyl pyrrolidone (NMP) at $110^{\circ} \mathrm{C}$. The theoretical investigation on APHDNE was curried out by B3LYP/ 6-311+G* method. The IR frequencies analysis and NMR chemical shifts were performed and compared with the experimental results. The thermal behavior of APHDNE was studied by DSC and TG/DTG methods, and can be divided into two crystal phase transition processes and three exothermic decomposition processes. The enthalpy, apparent activation energy and pre-exponential factor of the first exothermic decomposition reaction were obtained as $-525.3 \mathrm{~kJ} \mathrm{~mol}^{-1}, 276.85 \mathrm{~kJ} \mathrm{~mol}^{-1}$ and $10^{26.22} \mathrm{~s}^{-1}$, respectively. The critical temperature of thermal explosion of APHDNE is $237.7{ }^{\circ} \mathrm{C}$. The specific heat capacity of APHDNE was determined with micro-DSC method and theoretical calculation method, and the molar heat capacity is $363.67 \mathrm{~J} \mathrm{~mol}^{-1} \mathrm{~K}^{-1}$ at $298.15 \mathrm{~K}$. The adiabatic time-to-explosion of APHDNE was also calculated to be a certain value between 253.2-309.4 s. APHDNE has higher thermal stability than FOX-7.
\end{abstract}

Key Words : 1-Amino-1-(2,4-dinitrophenylhydrazinyl)-2,2-dinitroethylene (APHDNE), 1,1-Diamino-2,2dinitroethylene (FOX-7), Theoretical calculation, Thermal behavior, Adiabatic time-to-explosion

\section{Introduction}

1,1-Diamino-2,2-dinitroethylene (FOX-7) is a novel highenergy material with high thermal stability and low sensitivity to impact and friction. Since firstly synthesized in 1998, ${ }^{1,2}$ FOX-7 has attracted extensive attention and is considered as a promising low-sensitivity ammunition in future. Many researches have been carried out on the synthesis, mechanism, molecule structure, theoretical calculation, thermal behavior, explosive performance and application of FOX-7..$^{3-28}$

FOX-7 is a nitro-enamine belonging to the group of compounds known as "push-pull" alkenes. ${ }^{29}$ FOX-7 possesses a highly polarized carbon-carbon double bond, whose positive and negative charges are stabilized by two amino groups and two nitro groups respectively. Therefore, FOX-7 can react with some nucleophiles to form some new energetic compounds. Our interest mainly consisted in modifying molecular structure of FOX-7 in order to obtain new high-energy compounds and study their structure-property relationship. ${ }^{30-39}$

In this paper, we mainly reported the preparation and theoretical calculation of a new derivative of FOX-7, 1amino-1-(2,4-dinitrophenylhydrazinyl)-2,2-dinitroethylene (APHDNE), studied its thermal behavior with DSC and TG/ DTG methods, determined specific heat capacity with microDSC method and theoretical calculation method, and calculated adiabatic time-to-explosion for further estimating its thermal stability.

\section{Experimental}

Preparation of APHDNE. APHDNE was prepared according to the following method: FOX-7 (0.01 mol, 1.48 g) was dissolved in $12 \mathrm{~mL}$ of $N$-methylpyrrolidone (NMP) and to it 2,4-dinitrophenylhydrazine $(0.012 \mathrm{~mol}, 2.38 \mathrm{~g})$ was added drop wise. After reaction at $110^{\circ} \mathrm{C}$ for $24 \mathrm{~h}$, the resulting solution was slowly cooled to ambient temperature and diluted with proper amount of water. Many aubergine solid sediments were formed, which were filtered, washed with water, and dried under vacuum, yielding $1.28 \mathrm{~g}$ (39.2\%). Anal. calcd. for $\mathrm{C}_{8} \mathrm{H}_{7} \mathrm{~N}_{7} \mathrm{O}_{8}$ (\%): C 29.17, H 2.13, N 29.79; found (\%): C 28.96, H 2.24, N 30.47. IR (KBr) v 3277.5, 3095.9, 1653.1, 1612.9, 1455.0, 1357.4, 1304.6, 1092.6, $931.0 \mathrm{~cm}^{-1} .{ }^{13} \mathrm{C}$ NMR (DMSO, $400 \mathrm{MHz}, \delta$ ): 175.23, 144.13, $143.98,135.33,127.62,122.80,115.07,105.12 \mathrm{ppm}$.

Theoretical Calculation Investigation. A molecular unit of APHDNE generated from Chem3D software was selected as the initial structure model, while B3LYP/6-311+G* method in Gaussian 03 package $^{40}$ was used to optimize the structure and compute its frequencies at different temperatures and NMR chemical shifts. All convergent precisions are the system default values, and all calculations were carried out on the Lenovo computer.

Experimental Equipments and Conditions. The DSC experiments for APHDNE were performed using a DSCQ200 apparatus (TA, USA) under a nitrogen atmosphere at a flow rate of $50 \mathrm{~mL} \mathrm{~min} \mathrm{~m}^{-1}$ and the amount of used sample was about $1 \mathrm{mg}$. The heating rates used were 2.5, 5.0, 10.0 
and $15.0{ }^{\circ} \mathrm{C} \min ^{-1}$ from ambient temperature to $500.0{ }^{\circ} \mathrm{C}$, respectively.

The TG-DTG experiment for APHDNE was performed using a SDT-Q600 apparatus (TA, USA) under a nitrogen atmosphere at a flow rate of $100 \mathrm{~mL} \mathrm{~min}{ }^{-1}$. The amount of used sample was about $1.5 \mathrm{mg}$. The heating rate used was $5.0{ }^{\circ} \mathrm{C} \mathrm{min}{ }^{-1}$ from ambient temperature to $500.0^{\circ} \mathrm{C}$.

The specific heat capacity of APHDNE was measured using a Micro-DSCIII apparatus (SETARAM, France) with the sample amount of $277.14 \mathrm{mg}$. The heating rate was 0.15 ${ }^{\circ} \mathrm{C} \min ^{-1}\left(2.5 \times 10^{-3} \mathrm{~K} \mathrm{~s}^{-1}\right)$ from 10.0 to $80.0{ }^{\circ} \mathrm{C}$, in which the precisions of temperature and heat flow were $10^{-4}{ }^{\circ} \mathrm{C}$ and $0.2 \mu \mathrm{W}$, respectively. The principle for measuring of the continuous specific heat capacity is shown as:

$$
C_{\mathrm{p}}=\frac{A_{\mathrm{s}}-A_{\mathrm{b}}}{m_{\mathrm{s}} \times \beta}
$$

where $C_{\mathrm{p}}$ is the specific heat capacity, $A_{\mathrm{s}}$ and $A_{\mathrm{b}}$ are the heat flows of the sample and blank, $m_{\mathrm{s}}$ is the amount of the sample, $\beta$ is the heating rate.

\section{Results and Discussion}

The Reaction Mechanism. FOX-7 is a "push-pull" nitroenamine and possesses a highly polarized carbon-carbon double bond with positive and negative charges. ${ }^{6,10-12,29}$ 2,4Dinitrophenylhydrazine used as a kind of nucleophile attacks at the positive end of the carbon-carbon double bond, with subsequent replacement of one amino group by one 2,4-dinitrophenylhydrazine group. However, once one of the

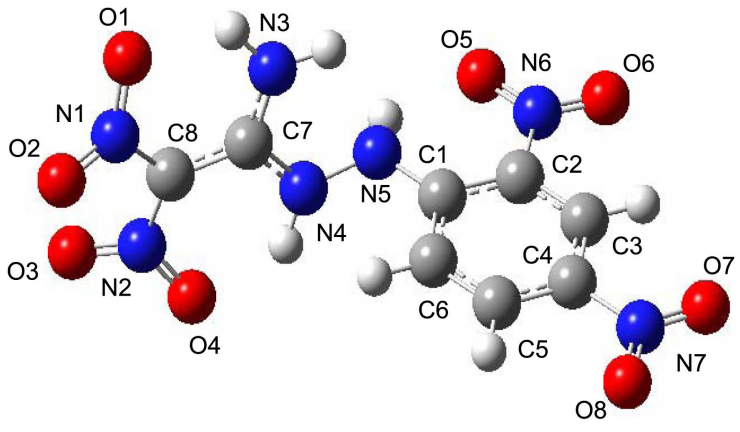

Figure 1. Optimized molecular structure of APHDNE.

two amino groups was substituted by the nucleophile, it was very difficult to replace the other one. The reason for the result should be that (1) the degree of the polarized carboncarbon double bond was considerablely weakened after the first-step replacement reaction, and (2) steric hindrance effect increased. Thus, we only synthesized 1-amino-1-(2,4dinitrophenylhydrazinyl)-2,2-dinitroethylene (APHDNE), rather than the alternative candidate, 1,1-bis-(2,4-dinitrophenylhydrazinyl)-2,2-dinitroethylene, despite in using different molar proportions of FOX-7 and 2,4-dinitrophenylhydrazine in our experiments.

Theoretical Calculation Results. Vibration analysis showed that the optimized structure is in accord with the minimum points on the potential energy planes, which means no virtual frequencies, proving that the optimized structure was stable and calculation results are reliable. Optimized molecular geometry and parameters are shown in

Table 1. Calculated non-hydrogen bond lengths, bond angles and mulliken net charges of APHDNE

\begin{tabular}{|c|c|c|c|c|c|c|c|}
\hline \multicolumn{8}{|l|}{ Bond length/Å } \\
\hline $\mathrm{N}(1)-\mathrm{O}(1)$ & 1.247 & $\mathrm{~N}(3)-\mathrm{C}(7)$ & 1.334 & $\mathrm{~N}(6)-\mathrm{C}(2)$ & 1.468 & $\mathrm{C}(2)-\mathrm{C}(3)$ & 1.393 \\
\hline $\mathrm{N}(1)-\mathrm{O}(2)$ & 1.216 & $\mathrm{~N}(4)-\mathrm{C}(7)$ & 1.361 & $\mathrm{~N}(7)-\mathrm{O}(7)$ & 1.224 & $C(3)-C(4)$ & 1.380 \\
\hline $\mathrm{N}(1)-\mathrm{C}(8)$ & 1.441 & $\mathrm{~N}(4)-\mathrm{N}(5)$ & 1.382 & $\mathrm{~N}(5)-\mathrm{O}(8)$ & 1.223 & $C(4)-C(5)$ & 1.396 \\
\hline $\mathrm{N}(2)-\mathrm{O}(3)$ & 1.215 & $\mathrm{~N}(5)-\mathrm{C}(1)$ & 1.384 & $\mathrm{~N}(7)-\mathrm{C}(4)$ & 1.474 & $C(5)-C(6)$ & 1.380 \\
\hline $\mathrm{N}(2)-\mathrm{O}(4)$ & 1.254 & $\mathrm{~N}(6)-\mathrm{O}(5)$ & 1.238 & $\mathrm{C}(1)-\mathrm{C}(2)$ & 1.422 & $C(7)-C(8)$ & 1.423 \\
\hline $\mathrm{N}(2)-\mathrm{C}(8)$ & 1.432 & $\mathrm{~N}(6)-\mathrm{O}(6)$ & 1.217 & $C(1)-C(6)$ & 1.410 & & \\
\hline \multicolumn{8}{|l|}{ Bond angles $/\left(^{\circ}\right)$} \\
\hline $\mathrm{O}(1)-\mathrm{N}(1)-\mathrm{O}(2)$ & 123.2 & $\mathrm{~N}(2)-\mathrm{C}(8)-\mathrm{C}(7)$ & 121.1 & $\mathrm{C}(1)-\mathrm{C}(2)-\mathrm{N}(6)$ & 122.7 & $\mathrm{C}(4)-\mathrm{N}(7)-\mathrm{O}(8)$ & 117.1 \\
\hline $\mathrm{O}(1)-\mathrm{N}(1)-\mathrm{C}(8)$ & 117.5 & $\mathrm{~N}(3)-\mathrm{C}(7)-\mathrm{C}(8)$ & 122.5 & $\mathrm{O}(5)-\mathrm{N}(6)-\mathrm{O}(6)$ & 123.6 & $\mathrm{~N}(7)-\mathrm{C}(4)-\mathrm{C}(5)$ & 119.7 \\
\hline $\mathrm{O}(2)-\mathrm{N}(1)-\mathrm{C}(8)$ & 119.2 & $\mathrm{~N}(3)-\mathrm{C}(7)-\mathrm{N}(4)$ & 116.9 & $\mathrm{O}(5)-\mathrm{N}(6)-\mathrm{C}(2)$ & 118.0 & $\mathrm{C}(1)-\mathrm{C}(6)-\mathrm{C}(5)$ & 121.6 \\
\hline $\mathrm{O}(3)-\mathrm{N}(2)-\mathrm{C}(8)$ & 119.8 & $\mathrm{~N}(4)-\mathrm{C}(7)-\mathrm{C}(8)$ & 120.6 & $\mathrm{O}(6)-\mathrm{N}(6)-\mathrm{C}(2)$ & 118.4 & $C(6)-C(5)-C(4)$ & 119.5 \\
\hline $\mathrm{O}(3)-\mathrm{N}(2)-\mathrm{O}(4)$ & 122.7 & $\mathrm{~N}(5)-\mathrm{N}(4)-\mathrm{C}(7)$ & 120.4 & $\mathrm{~N}(6)-\mathrm{C}(2)-\mathrm{C}(3)$ & 116.3 & $C(5)-C(4)-C(3)$ & 121.1 \\
\hline $\mathrm{O}(4)-\mathrm{N}(2)-\mathrm{C}(8)$ & 117.5 & $\mathrm{~N}(4)-\mathrm{N}(5)-\mathrm{C}(1)$ & 119.2 & $\mathrm{C}(3)-\mathrm{C}(4)-\mathrm{N}(7)$ & 119.3 & $\mathrm{C}(4)-\mathrm{C}(3)-\mathrm{C}(2)$ & 119.4 \\
\hline $\mathrm{N}(1)-\mathrm{C}(8)-\mathrm{N}(2)$ & 116.6 & $\mathrm{~N}(5)-\mathrm{C}(1)-\mathrm{C}(2)$ & 112.7 & $\mathrm{O}(7)-\mathrm{N}(7)-\mathrm{C}(4)$ & 117.6 & $\mathrm{C}(3)-\mathrm{C}(2)-\mathrm{C}(1)$ & 121.2 \\
\hline $\mathrm{N}(1)-\mathrm{C}(8)-\mathrm{C}(7)$ & 122.25 & $\mathrm{~N}(5)-\mathrm{C}(1)-\mathrm{C}(6)$ & 120.1 & $\mathrm{O}(7)-\mathrm{N}(7)-\mathrm{O}(8)$ & 125.3 & $\mathrm{C}(2)-\mathrm{C}(1)-\mathrm{C}(6)$ & 117.2 \\
\hline \multicolumn{8}{|c|}{ Mulliken net charges/e } \\
\hline $\mathrm{C}(1)$ & 0.032 & $C(7)$ & 0.538 & $\mathrm{~N}(5)$ & -0.577 & $\mathrm{O}(4)$ & -0.145 \\
\hline $\mathrm{C}(2)$ & -0.036 & $\mathrm{C}(8)$ & -0.146 & $\mathrm{~N}(6)$ & -0.247 & $\mathrm{O}(5)$ & -0.065 \\
\hline$C(3)$ & -0.129 & $\mathrm{~N}(1)$ & -0.195 & $\mathrm{~N}(7)$ & -0.219 & $\mathrm{O}(6)$ & 0.052 \\
\hline $\mathrm{C}(4)$ & -0.036 & $\mathrm{~N}(2)$ & -0.165 & $\mathrm{O}(1)$ & -0.132 & $\mathrm{O}(7)$ & 0.008 \\
\hline$C(5)$ & -0.801 & $\mathrm{~N}(3)$ & -0.776 & $\mathrm{O}(2)$ & 0.052 & $\mathrm{O}(8)$ & 0.001 \\
\hline$C(6)$ & 0.624 & $\mathrm{~N}(4)$ & -0.203 & $\mathrm{O}(3)$ & 0.078 & & \\
\hline
\end{tabular}


<smiles>N=C(NNc1ccc([N+](=O)[O-])cc1[N+](=O)[O-])C(N=O)=C(N)O[N+](=O)C=CC=O</smiles>

Scheme 1

Figure 1 and Table 1.

Substituting one amino group for one 2,4-dinitrophenylhydrazine group, the molecular symmetry was broken. Molecular space configuration (non-hydrogen atoms) changed greatly from the symmetric plane configuration to the asymmetric three dimensional configurations. ${ }^{2}$ The bond length of $\mathrm{C}(7)-\mathrm{C}(8)(1.42 \AA)$ is longer than the average length of C$\mathrm{C}$ double bond (1.32 $\AA$ ). The bond lengths of $\mathrm{N}(3)-\mathrm{C}(7)$ and $\mathrm{N}(4)-\mathrm{C}(7)$ (all equal to $1.34 \AA$ ) are shorter than the average length of C-N single bond (1.44 $\AA$ ), and close to the length of conjugated $\mathrm{C}-\mathrm{N}$ double bond $(1.28 \AA)$ ). All indicate that the obvious conjugative effect occurs between $\mathrm{C}(7)-\mathrm{C}(8)$, $\mathrm{C}(7)-\mathrm{N}(3)$ and $\mathrm{C}(7)-\mathrm{N}(4)$, and it can be concluded that APHDNE should be the following tautomer structure (conjugated structure) (Scheme 1). From the distribution of atomic net charges, we can see that $\mathrm{C}(7)$ atom has more positive charges and $\mathrm{C}(8)$ atom presents certain negative charges, indicating that APHDNE is also a typical nitroenamine compound and possesses a highly polarized carboncarbon double bond with positive and negative charges. All corresponding bond lengths and bond angles are in good agreement with these of FOX-7 and its other derivatives. ${ }^{2,30-34}$

On the basis of the simple harmonic oscillator analysis, 84 groups of frequency and intensity were obtained, only those

Table 2. Scaled IR frequencies for APHDNE

\begin{tabular}{|c|c|c|c|c|c|}
\hline$v / \mathrm{cm}^{-1}$ & $\begin{array}{c}I \\
/ \mathrm{km} \mathrm{mol}^{-1}\end{array}$ & $\begin{array}{l}\text { Exptl } \\
/ \mathrm{cm}^{-1}\end{array}$ & $v / \mathrm{cm}^{-1}$ & $\begin{array}{c}I \\
/ \mathrm{km} \mathrm{mol}^{-1}\end{array}$ & $\begin{array}{l}\text { Exptl } \\
/ \mathrm{cm}^{-1}\end{array}$ \\
\hline 726 & 19.5 & & 1318 & 247.1 & \\
\hline 730 & 20.7 & & 1348 & 176.5 & 1333 \\
\hline 753 & 18.2 & & 1357 & 462.9 & \\
\hline 756 & 22.6 & 766 & 1373 & 109.3 & 1357 \\
\hline 776 & 24.8 & & 1415 & 39.4 & \\
\hline 811 & 49.6 & & 1442 & 4.6 & 1455 \\
\hline 848 & 24.5 & 841 & 1483 & 117.4 & \\
\hline 857 & 22.1 & & 1534 & 191.0 & \\
\hline 864 & 11.6 & & 1563 & 533.6 & \\
\hline 888 & 34.8 & & 1578 & 61.3 & \\
\hline 937 & 38.3 & & 1588 & 195.5 & 1584 \\
\hline 962 & 15.3 & & 1602 & 929.7 & \\
\hline 1053 & 10.4 & & 1609 & 64.0 & 1613 \\
\hline 1080 & 62.0 & & 1639 & 228.4 & \\
\hline 1112 & 35.3 & 1093 & 1654 & 215.1 & 1653 \\
\hline 1146 & 46.1 & & 1663 & 344.3 & \\
\hline 1161 & 96.5 & & 3247 & 24.9 & 3096 \\
\hline 1201 & 81.1 & & 3442 & 206.3 & \\
\hline 1252 & 270.9 & & 3515 & 133.4 & 3277 \\
\hline 1269 & 241.6 & & 3525 & 120.9 & \\
\hline 1302 & 147.0 & 1305 & 3677 & 194.1 & \\
\hline
\end{tabular}

large than $700 \mathrm{~cm}^{-1}$ are listed in Table 2 . The scaled IR frequencies were calibrated by multiplying 0.96 . Due to the complexity of vibrational mode, we only analyzed some typical vibrational modes comparing with the experimental data. The theoretical value at $3247 \mathrm{~cm}^{-1}$ caused by the $\mathrm{C}-\mathrm{H}$ (Benzene) stretching vibration is in agreement with that of the experiment $\left(3096 \mathrm{~cm}^{-1}\right)$. The theoretical value at 3525 $\mathrm{cm}^{-1}$ caused by the $\mathrm{N}-\mathrm{H}\left(-\mathrm{NH}_{2}\right)$ stretching vibration is in agreement with that of the experiment $\left(3277 \mathrm{~cm}^{-1}\right)$. The asymmetric and symmetric characteristic absorption peaks of $\mathrm{C}-\mathrm{N}\left(-\mathrm{NO}_{2}\right)$ are found to be 1112 and $1373 \mathrm{~cm}^{-1}$, relevant to the experimental values of 1093 and $1357 \mathrm{~cm}^{-1}$. The theoretical value at $1654 \mathrm{~cm}^{-1}$ caused by the $\mathrm{C}=\mathrm{C}$ stretching vibration is consistent with that of the experiment (1653 $\mathrm{cm}^{-1}$ ). The absorption peak of the benzene skeleton vibration is found to be at 1442 and $1639 \mathrm{~cm}^{-1}$, relevant to the experimental values of 1455 and $1653 \mathrm{~cm}^{-1}$.

Through NMR calculation, we got eight values of the chemical shifts of ${ }^{13} \mathrm{C}$, which are listed in Table 3. In comparison with the corresponding experimental data, the calculated results deviate slightly, since the calculation of theoretical properties is based on single gas phase molecule.

Thermal Behavior. From the typical DSC and TG/DTG curves (Figs. 2 and 3), we can see that the thermal behavior of APHDNE can be divided into five stages. The first two stages are crystal phase transition processes, and the peak temperatures are 115.37 and $192.37^{\circ} \mathrm{C}$ at the heating rate of $5.0^{\circ} \mathrm{C} \mathrm{min}^{-1}$. The last three stages are the continuous exothermic decomposition processes. The peak temperatures are 244.67, 295.47 and $376.57{ }^{\circ} \mathrm{C}$ at the heating rate of $5.0{ }^{\circ} \mathrm{C}$ $\mathrm{min}^{-1}$, respectively. The thermal behavior was markedly different from that of FOX-7, whose thermal behavior presents only two obvious exothermic decomposition processes, and the peak temperatures of the two processes are 230.1 and $295.5^{\circ} \mathrm{C}$ at the heating rate of $10.0^{\circ} \mathrm{C} \mathrm{min}{ }^{-1} .{ }^{12} \mathrm{We}$ can see that the thermal decomposition temperature and thermal stability of the compound are improved greatly, after reacting with 2,4-dinitrophenylhydrazine. Comparing the result with that of another derivative of FOX-7, 1-amino-1hydrazino-2,2-dinitroethylene (AHDNE), whose thermal behavior presents two continuous exothermic decomposition processes, and the peak temperatures of the two processes are 113.0 and $133.7^{\circ} \mathrm{C}$ at the heating rate of $5.0^{\circ} \mathrm{C} \mathrm{min}{ }^{-132}$, APHDNE presents much higher thermal stability than

Table 3. ${ }^{13} \mathrm{C}$ NMR chemical shifts

\begin{tabular}{ccc}
\hline NMR chemical shifts & Calcd/ppm & Expt1/ppm \\
\hline$\delta(\mathrm{C} 1)$ & 155.50 & 144.13 \\
$\delta(\mathrm{C} 2)$ & 140.52 & 127.62 \\
$\delta(\mathrm{C} 3)$ & 130.26 & 115.07 \\
$\delta(\mathrm{C} 4)$ & 148.95 & 143.98 \\
$\delta(\mathrm{C} 5)$ & 137.53 & 122.79 \\
$\delta(\mathrm{C} 6)$ & 117.24 & 105.12 \\
$\delta(\mathrm{C} 7)$ & 159.30 & 175.23 \\
$\delta(\mathrm{C} 8)$ & 140.39 & 135.43 \\
\hline
\end{tabular}




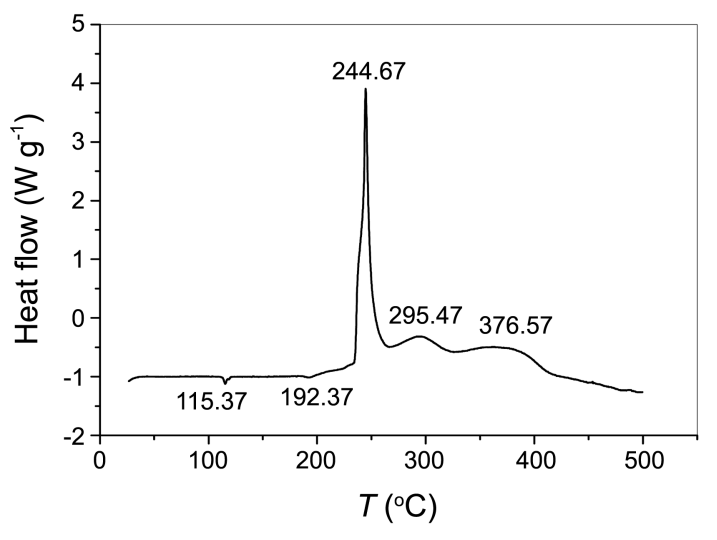

Figure 2. DSC curve of APHDNE at a heating rate of $5.0{ }^{\circ} \mathrm{C} \mathrm{min}^{-1}$.

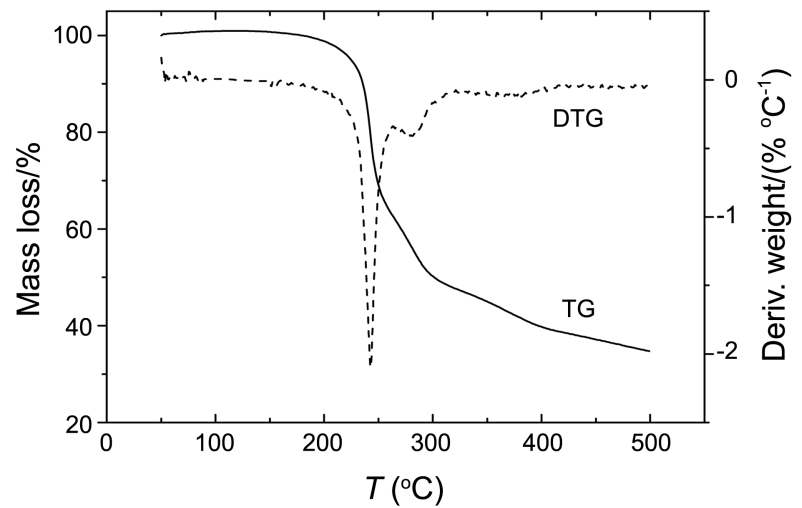

Figure 3. TG-DTG curves of APHDNE at a heating rate of $5.0{ }^{\circ} \mathrm{C}$ $\min ^{-1}$.

AHDNE. From the above results, we can see that the group behind hydrazine has a great influence on the properties of compound.

In order to obtain the kinetic parameters (the apparent activation energy $(E)$ and pre-exponential factor $(A))$ of the first exothermic decomposition reaction for APHDNE, a multiple heating method (Kissinger method ${ }^{41}$ and Ozawa method $^{42}$ ) was employed (Fig. 4). The Kissinger and Ozawa equations are as follows:

Kissinger Eq.: $\ln \left(\frac{\beta}{T_{\mathrm{p}}^{2}}\right)=\ln \frac{A R}{E_{\mathrm{k}}}-\frac{E_{\mathrm{k}}}{R} \frac{1}{T_{\mathrm{p}}}$

Ozawa Eq.: $\quad \log \beta+\frac{0.4567 E_{\mathrm{o}}}{R T_{\mathrm{p}}}=C$

where $\beta$ is the linear heating rate, $T_{\mathrm{p}}$ is the peak temperature, $A$ is the pre-exponential constant, $R$ is the gas constant, $E$ is

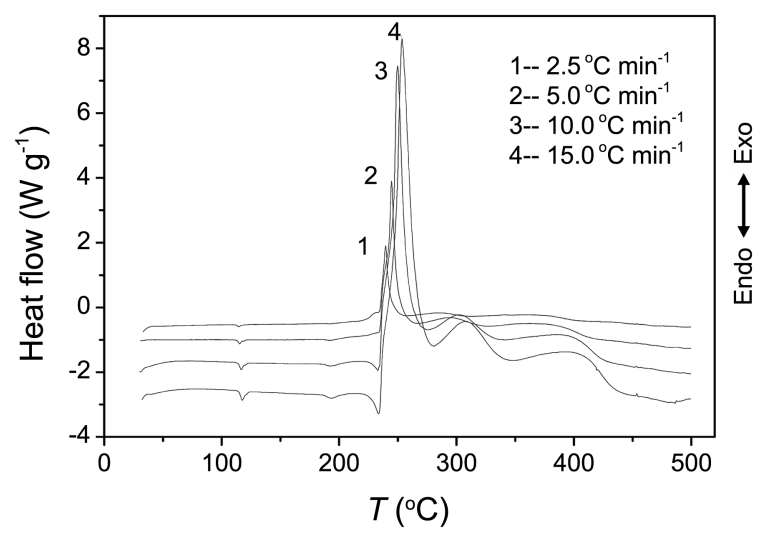

Figure 4. DSC curves of APHDNE at various heating rates.

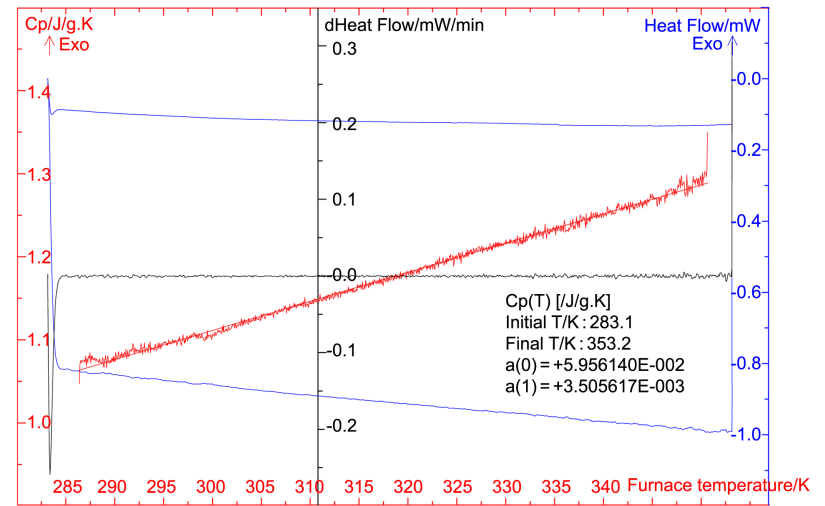

Figure 5. Determination results of the continuous $C_{\mathrm{p}}$ of APHDNE.

the apparent activation energy and $C$ is a constant.

The measured values of the beginning temperature $\left(T_{0}\right)$, extrapolated onset temperature $\left(T_{\mathrm{e}}\right)$, peak temperature $\left(T_{\mathrm{p}}\right)$ and enthalpy $\left(\Delta H_{\mathrm{d}}\right)$ of the first exothermic decomposition reaction were listed in Table 4 . The values $\left(T_{00}, T_{\mathrm{e} 0}\right.$ and $\left.T_{\mathrm{p} 0}\right)$ of $T_{0}, T_{\mathrm{e}}$ and $T_{\mathrm{p}}$ corresponding to $\beta \rightarrow 0$ obtained by Eq. (4) were also listed in Table $4 .{ }^{43}$

$$
T_{(0, e \text { or } \mathrm{p}) i}=T_{(00, e 0 \text { or } \mathrm{p} 0)}+n \beta_{i}+m \beta_{i}^{2} \quad i=1-4
$$

where $n$ and $m$ are coefficients.

The results obtained by Kissinger and Ozawa methods were listed in Table 5. We can see that the apparent activation energy obtained by Kissinger method agrees well with that by Ozawa method. All the linear correlation coefficients $(r)$ are very close to 1 . So, the results are credible. Moreover, we can see that the apparent activation energy is higher, which indicates that the thermal stability of APHDNE is good.

Table 4. The values of $T_{0}, T_{\mathrm{e}}, T_{\mathrm{p}}, \Delta H_{\mathrm{d}}, T_{00}, T_{\mathrm{e} 0}$ and $T_{\mathrm{p} 0}$ of the thermal decomposition by DSC curves at various heating rates $(\beta)$

\begin{tabular}{|c|c|c|c|c|c|c|c|}
\hline$\beta /\left({ }^{\circ} \mathrm{C} \min ^{-1}\right)$ & $T_{0} /{ }^{\circ} \mathrm{C}$ & $T_{\mathrm{e}} /{ }^{\circ} \mathrm{C}$ & $T_{\mathrm{p}} /{ }^{\circ} \mathrm{C}$ & $\Delta H_{\mathrm{d}} /\left(\mathrm{kJ} \mathrm{mol}^{-1}\right)$ & $T_{00} /{ }^{\circ} \mathrm{C}$ & $T_{\mathrm{e} 0} /{ }^{\circ} \mathrm{C}$ & $T_{\mathrm{p} 0} /{ }^{\circ} \mathrm{C}$ \\
\hline 2.5 & 213.58 & 235.19 & 239.48 & \multirow{4}{*}{-525.3} & \multirow{4}{*}{209.84} & \multirow{4}{*}{229.75} & \multirow{4}{*}{235.01} \\
\hline 5.0 & 217.50 & 241.15 & 244.67 & & & & \\
\hline 10.0 & 221.58 & 244.85 & 249.68 & & & & \\
\hline 15.0 & 224.13 & 245.51 & 253.62 & & & & \\
\hline
\end{tabular}


Table 5. The kinetic parameters obtained by the data in Table $1^{a}$

\begin{tabular}{cccccc}
\hline$E_{\mathrm{k}} /\left(\mathrm{kJ} \mathrm{mol}^{-1}\right)$ & $\log \left(A / \mathrm{s}^{-1}\right)$ & $r_{\mathrm{k}}$ & $E_{\mathrm{O}} /\left(\mathrm{kJ} \mathrm{mol}^{-1}\right)$ & $r_{\mathrm{O}}$ & $\bar{E} /\left(\mathrm{kJ} \mathrm{mol}^{-1}\right)$ \\
\hline 279.6 & 26.22 & 0.9987 & 274.1 & 0.9988 & 276.85 \\
\hline
\end{tabular}

${ }^{a}$ Subscript k, data obtained by Kissinger's method; subscript o, data obtained by Ozawa's method.

The critical temperature of thermal explosion $\left(T_{\mathrm{b}}\right)$ obtained by Eq. $(5)^{43}$ is $237.7^{\circ} \mathrm{C}$, which is higher than that of FOX-7 as $207.1^{\circ} \mathrm{C},,^{12}$ and AHDNE as $98.2^{\circ} \mathrm{C},{ }^{32}$ indicating that APHDNE presents higher thermal stability than FOX-7 and AHDNE.

$$
T_{\mathrm{b}}=\frac{E_{\mathrm{O}}-\sqrt{E_{\mathrm{O}}^{2}-4 E_{\mathrm{O}} R T_{\mathrm{e} 0}}}{2 R}
$$

where $E_{\mathrm{O}}$ is the value of $E$ by Ozawa's method.

The entropy of activation $\left(\Delta S^{\neq}\right)$, enthalpy of activation $\left(\Delta H^{\ddagger}\right)$ and free energy of activation $\left(\Delta G^{\ddagger}\right)$ of the first exothermic decomposition stage corresponding to $T=T_{\mathrm{p} 0}$ and $E$ $=E_{\mathrm{k}}$ obtained by Eqs. (6)-(8) ${ }^{43}$ are $252.6 \mathrm{~J} \mathrm{~mol}^{-1} \mathrm{~K}^{-1}, 279.6$ $\mathrm{kJ} \mathrm{mol}^{-1}$ and $151.2 \mathrm{~kJ} \mathrm{~mol}^{-1}$, respectively.

$$
\begin{aligned}
& A=\frac{k_{\mathrm{B}} T}{h} \exp \left(\frac{\Delta S^{\ddagger}}{R}\right) \\
& A \exp \left(-\frac{E}{R T}\right)=\frac{k_{\mathrm{B}} T}{h} \exp \left(\frac{\Delta S^{\ddagger}}{R}\right) \exp \left(-\frac{\Delta H^{\ddagger}}{R T}\right) \\
& \Delta S^{\neq}=\Delta H^{\neq}-T \Delta S^{\neq}
\end{aligned}
$$

where $k_{\mathrm{B}}$ is the Boltzman constant and $h$ is the Plank constant.

Specific Heat Capacity. Figure 5 shows the determination results of APHDNE using a continuous specific heat capacity mode of Micro-DSCIII apparatus. We can see that the specific heat capacity of APHDNE presents a good linear relationship with temperature in determining temperature range. Specific heat capacity equation is shown as:

$$
\begin{aligned}
C_{\mathrm{p}}\left(\mathrm{J} \mathrm{g}^{-1} \mathrm{~K}^{-1}\right)= & 5.9561 \times 10^{-2}+3.5056 \times 10^{-3} T \\
& (283.0 \mathrm{~K}<T<353.0 \mathrm{~K})
\end{aligned}
$$

The molar heat capacity of APHDNE is $363.67 \mathrm{~J} \mathrm{~mol}^{-1} \mathrm{~K}^{-1}$ at $298.15 \mathrm{~K}$.

Table 6 shows the results of specific heat capacity by the theoretical calculation and experimental determination and their relative deviations at different temperatures. We can see that the calculated results are all less than the experimental results, and the relative deviations are comparatively great, from $12.88 \%$ to $16.46 \%$. This is attributed to single gas phase molecule used in theoretical calculation, which is clearly different to the actual solid phase molecule.

Thermodynamic Properties. The enthalpy change, entropy change and Gibbs free energy change of APHDNE were calculated by Eqs. (10)-(12) at 283-353 K, from ambient temperature to thermal decomposition temperature, taking $298.15 \mathrm{~K}$ as the benchmark. The results were listed in Table 7.

$$
H_{T}-H_{298.15}=\int_{298.15}^{T} C_{\mathrm{p}} \mathrm{d} T
$$

Table 6. Results of specific heat capacity by the theoretical calculation and experimental determination and their relative deviation at different temperatures

\begin{tabular}{cccc}
\hline \multirow{2}{*}{$\begin{array}{c}\text { Temperature } \\
\text { /K }\end{array}$} & \multicolumn{2}{c}{$C_{\mathrm{p}} /\left(\mathrm{J} \mathrm{mol}^{-1} \mathrm{~K}^{-1}\right)$} & \multirow{2}{R}{$\begin{array}{c}\mathrm{RD} \\
/ \%\end{array}$} \\
\cline { 2 - 3 } & $\begin{array}{c}\text { Theoretical } \\
\text { calculation value }\end{array}$ & $\begin{array}{c}\text { Experimental } \\
\text { value }\end{array}$ & \\
\hline 283.0 & 301.61 & 346.19 & 12.88 \\
293.0 & 309.69 & 357.73 & 13.43 \\
298.15 & 313.81 & 363.67 & 13.71 \\
303.0 & 317.66 & 369.27 & 13.98 \\
313.0 & 325.51 & 380.81 & 14.52 \\
323.0 & 333.23 & 392.35 & 15.07 \\
333.0 & 340.82 & 403.89 & 15.62 \\
343.0 & 348.29 & 415.43 & 16.16 \\
353.0 & 355.62 & 426.97 & 16.71 \\
\hline
\end{tabular}

Table 7. Thermodynamic function data of APHDNE

\begin{tabular}{cccc}
\hline$T / \mathrm{K}$ & $\begin{array}{c}H_{T}-H_{298.15} \\
/\left(\mathrm{kJ} \mathrm{mol}^{-1}\right)\end{array}$ & $\begin{array}{c}S_{T}-S_{298.15} \\
/\left(\mathrm{J} \mathrm{mol}^{-1} \mathrm{~K}^{-1}\right)\end{array}$ & $\begin{array}{c}G_{T}-G_{298.15} \\
/\left(\mathrm{kJ} \mathrm{mol}^{-1}\right)\end{array}$ \\
\hline 283.0 & -5.3772 & -18.5054 & -0.1401 \\
293.0 & -1.8576 & -6.2847 & -0.0162 \\
303.0 & 1.7774 & 5.9132 & -0.0143 \\
313.0 & 5.5277 & 18.0898 & -0.1344 \\
323.0 & 9.3935 & 30.2463 & -0.3761 \\
333.0 & 13.3746 & 42.3840 & -0.7392 \\
343.0 & 17.4712 & 54.5040 & -1.2237 \\
353.0 & 21.6831 & 66.6074 & -1.8293 \\
\hline
\end{tabular}

$$
\begin{aligned}
& S_{T}-S_{298.15}=\int_{298.15}^{T} C_{\mathrm{p}} T^{-1} \mathrm{~d} T \\
& G_{T}-G_{298.15}=\int_{298.15}^{T} C_{\mathrm{p}} \mathrm{d} T-T \int_{298.15}^{T} C_{\mathrm{p}} T^{-1} \mathrm{~d} T
\end{aligned}
$$

Estimation of Adiabatic Time-to-explosion. Energetic materials need a time from the beginning thermal decomposition to thermal explosion in adiabatic condition. We called the time as the adiabatic time-to-explosion. ${ }^{35-39,43-47}$ Ordinarily, we use heating rate $(\mathrm{d} T / \mathrm{d} t)$ and critical heating rate $(\mathrm{d} T / \mathrm{d} t)_{T_{\mathrm{b}}}$ in thermal decomposition process to evaluate the thermal stability of energetic materials. However, we can calculate the adiabatic time-to-explosion $(t)$ by the following Eqs. (13)-(14) $35-39,44-47$ when we have obtained a series of experimental data. Thereby, as an important parameter, it is easy and intuitionistic to evaluate the thermal stability of energetic materials according to the length of the adiabatic time-to-explosion.

$$
C_{\mathrm{p}} \frac{\mathrm{d} T}{\mathrm{~d} t}=Q A \exp (-E / R T) f(\alpha)
$$




$$
\alpha=\int_{T_{0}}^{T} \frac{C_{\mathrm{p}}}{Q} \mathrm{~d} T
$$

where $C_{\mathrm{p}}$ is the specific heat capacity $\left(\mathrm{J} \mathrm{mol}^{-1} \mathrm{~K}^{-1}\right), T$ is the absolute temperature $(\mathrm{K}), t$ is the adiabatic time-to-explosion (s), $Q$ is the exothermic values $\left(\mathrm{J} \mathrm{mol}^{-1}\right), A$ is the preexponential factor $\left(\mathrm{s}^{-1}\right), E$ is the apparent activation energy the thermal decomposition reaction $\left(\mathrm{J} \mathrm{mol}^{-1}\right), R$ is the gas constant $\left(\mathrm{J} \mathrm{mol}^{-1} \mathrm{~K}^{-1}\right), f(\alpha)$ is the most probable kinetic model function and $\alpha$ is the fraction of conversion.

According to the above determining results of APHDNE, we use:

$$
C_{\mathrm{p}}=a+b T
$$

where $a$ and $b$ are coefficients.

In fact, the conversion degree $(\alpha)$ of energetic materials from the beginning thermal decomposition to thermal explosion in the adiabatic conditions is small, and the most probable kinetic model function $[f(\alpha)]$ at this beginning decomposition process is unimportant on the result of the estimation of the adiabatic time-to-explosion. So, we used Eq. (16) and supposed that the rate order of the mechanism function $(n)$ of APHDNE in the process equaled 0,1 and $2^{22,32,33}$

$$
f(\alpha)=(1-\alpha)^{n}
$$

The combination of Eqs. (13)-(16) gives the following adiabatic time-to-explosion equation:

$$
\begin{aligned}
t= & \int_{0}^{t} \mathrm{~d} t=\int_{T_{0}}^{T} \frac{C_{\mathrm{p}} \exp (E / R T)}{Q A f(\alpha)} \mathrm{d} T \\
= & \frac{1}{Q A} \int_{T_{0}}^{T} \frac{(a+b T) \exp (E / R T)}{(1-\alpha)^{n}} \mathrm{~d} T \\
= & \frac{1}{Q A\left\{1-\frac{1}{Q}\left[a\left(T_{\mathrm{b}}-T_{00}\right)+\frac{b}{2}\left(T_{\mathrm{b}}^{2}-T_{00}^{2}\right)\right]\right\}^{n}} \\
& \int_{T_{0}}^{T}(a+b T) \exp (E / R T) \mathrm{d} T
\end{aligned}
$$

The limit of temperature integral in Eq. (17) is from $T_{00}$ to $T_{\mathrm{b}}$. We can directly get $t_{0}=253.2 \mathrm{~s}, t_{1}=279.9 \mathrm{~s}$ and $t_{2}=309.4 \mathrm{~s}$ from Eq. (17), according to the above obtained data. As a rule, the rate $\operatorname{order}(n)$ of energetic materials ranges from 0 to 2 , so the adiabatic time-to-explosion of APHDNE is a certain value between 253.2-309.4 $\mathrm{s}$. The time is much longer than that of FOX-7 as 78.9-88.9 $\mathrm{s}^{22}$ and AHDNE as $59.2 \mathrm{s.}^{32}$ The sequence of the adiabatic time-to-explosion is well consistent with that of the critical temperature of thermal explosion for the three corresponding compounds. In another aspect, it further proves the higher thermal stability of APHDNE than those of FOX-7 and AHDNE.

\section{Conclusions}

(1) APHDNE was synthesized and theoretical investigation was carried out with B3LYP/6-311+G* method in Gaussian
03 package. The thermal behavior of APHDNE can be divided into two crystal phase transition processes and three exothermic decomposition processes. The enthalpy, apparent activation energy and pre-exponential factor of the first exothermic decomposition reaction were obtained as -525.3 $\mathrm{kJ} \mathrm{mol}^{-1}, 276.85 \mathrm{~kJ} \mathrm{~mol}^{-1}$ and $10^{26.22} \mathrm{~s}^{-1}$, respectively. The critical temperature of thermal explosion of APHDNE is $237.7^{\circ} \mathrm{C}$.

(2) The specific heat capacity of APHDNE was studied. Specific heat capacity equation is $C_{\mathrm{p}}\left(\mathrm{J} \mathrm{g}^{-1} \mathrm{~K}^{-1}\right)=5.9561 \times$ $10^{-2}+3.5056 \times 10^{-3} T(283.0 \mathrm{~K}<T<353.0 \mathrm{~K})$ and the molar heat capacity is $363.67 \mathrm{~J} \mathrm{~mol}^{-1} \mathrm{~K}^{-1}$ at $298.15 \mathrm{~K}$. The adiabatic time-to-explosion of APHDNE was also calculated to be a certain value between 253.2-309.4 s. APHDNE has higher thermal stability than FOX-7 and AHDNE.

Acknowledgments. This research was supported by the National Natural Science Foundation of China (No. 20803058), Basal Science Foundation of National Defense (No. B0920110005), Shaanxi Science Research Program (No. 2011kjxx31) and Education Committee Foundation of Shaanxi Province (No. 2010JK881).

\section{References}

1. Latypov, N. V.; Bergman, J.; Langlet, A.; Wellmar, U.; Bemm, U. Tetrahedron 1998, 54, 11525.

2. Bemm, U.; Ötmark, H. Acta Cryst. C 1998, 54, 1997.

3. Gindulyte, A.; Massa, L.; Huang, L.; Karle, J. J. Phys. Chem. A 1999, 103, 11045.

4. Sorescu, D. C.; Boatz, J. A.; Thopmson, D. L. J. Phys. Chem. A 2001, 105, 5010 .

5. Ji, G. F.; Xiao, H. M.; Dong, H. S.; Gong, X. D.; Li, J. S.; Wang, Z. Y. Acta Chim. Sinica 2001, 59, 39.

6. Bellamy, A. J.; Goede, P.; Sandberg, C.; Latypov, N. V. The Proceedings of the 33th International Annual Conference; ICT, Karlsruke, Germany, 2002.

7. Sorescu, D. C.; Boatz, J. A.; Thompson, D. L. J. Phys. Chem. B 2003, 107, 8953 .

8. Cai, H. Q.; Shu, Y. J.; Huang, H.; Cheng, B. B.; Li, J. S. J. Org. Chem. 2004, 69, 4369.

9. Cai, H. Q.; Shu, Y. J.; Yu, W. F.; Li, J. S.; Cheng, B. B. Acta Chim. Sinica 2004, 62, 295.

10. Hervé, G.; Jacob, G.; Latypov, N. Tetrahedron 2005, 61, 6743.

11. Sorescu, D. C.; Boatz, J. A.; Thompson, D. L. J. Phys. Chem. B 2005, 109, 1451.

12. Gao, H. X.; Zhao, F. Q.; Hu, R. Z.; Pan, Q.; Wang, B. Z.; Yang, X. W.; Gao, Y.; Gao, S. L.; Shi, Q. Z. Chin. J. Chem. 2006, 24, 177.

13. Anniyappan, M.; Talawar, M. B.; Gore, G. M.; Venugopalan, S.; Gandhe, B. R. J. Hazard. Mater. 2006, 137, 812.

14. Trzciński, W. A.; Cudzilo, S.; Chylek, Z.; Szymańczyk, L. J. Hazard. Mater. 2006, 157, 605.

15. Evers, J.; Klapotke, T. M.; Mayer, P.; Oehlinger, G.; Welch, J. Inorg. Chem. 2006, 45, 4996.

16. Zerilli, F. J.; Kuklja, M. M. J. Phys. Chem. A 2006, 110, 5173.

17. Zerilli, F. J.; Kuklja, M. M. J. Phys. Chem. A 2007, 111, 1721.

18. Hervé, G.; Jacob, G.; Latypov, N. Tetrahedron 2007, 63, 953.

19. Majano, G.; Mintova, S.; Bein, T.; Klapötke, T. M. J. Phys. Chem. C 2007, 111, 3394.

20. Latypov, N. V.; Johansson, M.; Holmgren, E.; Sizova, E. V.; Sizov, V. V.; Bellamy, A. J. Org. Process Res. Dev. 2007, 11, 56.

21. Fan, X. Z.; Li, J. Z.; Liu, Z. R. J. Phys. Chem. A 2007, 111, 13291. 22. Xu, K. Z.; Song, J. R.; Zhao, F. Q.; Cao, Z. H.; Ma, H. X.; Hu, R. 
Z.; Gao, H. X.; Huang, J. Acta Chim. Sinica 2007, 65, 2827.

23. Zhao, J. J.; Liu, H. Comp. Mater. Sci. 2008, 42, 698.

24. Kimmel, A. V.; Sushko, P. V.; Shluger, A. L.; Kuklja, M. M. J. Phys. Chem. A 2008, 112, 4496.

25. Buszewski, B.; Michel, M.; Cudzilo, S.; Chylek, Z. J. Hazard. Mater. 2009, 164, 1051.

26. Xing, X. L.; Xue, L.; Zhao, F. Q.; Gao, H. X.; Hu, R. Z. Thermochim. Acta 2009, 491, 35.

27. Buszewski, B.; Michel, M.; Cudzilo, S.; Chylek, Z. J. Hazard. Mater. 2009, 164, 1051.

28. Ahn, J. H.; Kim, J. K.; Kim, H. S.; Kim, E. J.; Koo, K. K. J. Chem. Eng. Data 2009, 54, 3259.

29. Rajappa, S. Tetrahedron 1981, 37, 1453.

30. Xu, K. Z.; Song, J. R.; Yang, X.; Chang, C. R.; Yang, X. K.; Ma, H. X.; Huang, J.; Zhao, F. Q. J. Mole. Struct. 2008, 891, 340.

31. Chang, C. R.; Xu, K. Z.; Song, J. R.; Yan, B.; Ma, H. X.; Gao, H. X.; Zhao, F. Q. Acta Chim. Sinica 2008, 66, 1399 (in Chinese).

32. Xu, K. Z.; Zhao, F. Q.; Song, J. R.; Chang, C. R.; Li, M.; Wang, Y. Y.; Hu, R. Z. Chin. J. Chem. 2009, 27, 665.

33. Xu, K. Z.; Chang, C. R.; Song, J. R.; Zhao, F. Q.; Ma, H. X.; Lv, X. Q.; Hu, R. Z. Chin. J. Chem. 2008, 26, 495.

34. She, J. N.; Xu, K. Z.; Zhang, H.; Huang, J.; Zhao, F. Q.; Song, J. R. Acta Chim. Sinica 2009, 67, 2645. (in Chinese)

35. Xu, K. Z.; Zhao, F. Q.; Song, J. R.; Ren, X. L.; Gao, H. X.; Xu, S.
Y.; Hu, R. Z. Bull. Korean Chem. Soc. 2009, 30, 2259.

36. Xu, K. Z.; Song, J. R.; Zhao, F. Q.; Heng, S. Y.; Ding, L.; Wang, Y. Y.; Hu, R. Z. J. Chin. Chem. Soc. 2009, 56, 524.

37. Xu, K. Z.; Wang, F.; Ren, Y. H.; Li, W. H.; Zhao, F. Q.; Chang, C. R.; Song, J. R. Chin. J. Chem. 2010, 28, 583.

38. Xu, K. Z.; Zuo, X. G.; Song, J. R.; Wang, F.; Huang, J.; Chang, C. R. Chem. J. Chin. Univer. 2010, 31, 638. (in Chinese)

39. Xu, K. Z.; Zhao, F. Q.; Wang, F.; Wang, H.; Luo, J. A.; Hu, R. Z. Chin. J. Chem. Phys. 2010, 23, 335.

40. Frisch, M. J.; Trucks, G. W.; Schlegel, H. B. et al. Gaussian 03, Revision B.01, Gaussian, Inc.: Pittsburgh PA 2003.

41. Kissinger, H. E. Anal. Chem. 1957, 29, 1702.

42. Ozawa, T. Bull. Chem. Soc. Jpn. 1965, 38, 1881.

43. Hu, R. Z.; Gao, S. L.; Zhao, F. Q.; Shi, Q. Z.; Zhang, T. L.; Zhang, J. J. Thermal Analysis Kinetics $\left(2^{\text {th }}\right)$, Science Press: Beijing, 2008. (in Chinese)

44. Smith, L. C. Thermochim. Acta 1975, 13, 1.

45. Xu, K. Z.; Song, J. R.; Zhao, F. Q.; Ma, H. X.; Gao, H. X.; Chang, C. R.; Ren, Y. H.; Hu, R. Z. J. Hazard. Mater. 2008, 158, 333.

46. Xu, K. Z.; Ren, X. L.; Song, J. R.; Zhao, F. Q.; Ding, L.; Yi, J. H.; Wang, Y. Y. Chin. J. Chem. 2009, 27, 1907.

47. Ma, H. X.; Yan, B.; Li, Z. N.; Song, J. R.; Hu, R. Z. J. Therm. Anal. Calorim. 2009, 95, 437. 